\title{
HPV self-sampling in cervical cancer screening: the effect of different invitation strategies in various socioeconomic groups - a randomized controlled trial
}

This article was published in the following Dove Press journal:

Clinical Epidemiology

Mette Tranberg, ${ }^{1,2}$ Bodil

Hammer Bech, ${ }^{3}$ Jan Blaakær, ${ }^{4,5}$

Jørgen Skov Jensen, ${ }^{6}$ Hans

Svanholm, ${ }^{1,7}$ Berit Andersen ${ }^{1,2}$

'Department of Public Health Programmes, Randers Regional Hospital, Randers,

Denmark; '2Department of Clinical Medicine,

Aarhus University, Aarhus, Denmark;

${ }^{3}$ Section for Epidemiology, Department of

Public Health, Aarhus University, Aarhus,

Denmark; ${ }^{4}$ Department of Obstetrics and

Gynecology, Odense University Hospital,

Odense, Denmark; ${ }^{5}$ Department of

Clinical Medicine, University of Southern

Denmark, Odense, Denmark; ${ }^{6}$ Research

Unit for Reproductive Microbiology, Statens

Serum Institut, Copenhagen, Denmark

'Department of Pathology, Randers Regional

Hospital, Randers, Denmark

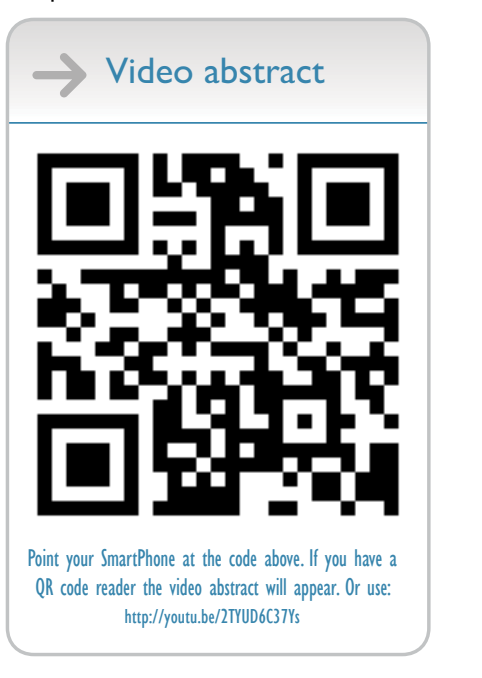

Correspondence: Mette Tranberg

Department of Public Health Programmes,

Randers Regional Hospital, Skovlyvej 15, 8930

Randers NØ, Denmark

$\mathrm{Tel}+4578420264$

Email mettrani@rm.dk
Background: Participation in cervical cancer screening varies by socioeconomic status. The aims were to assess if offering human papilloma virus (HPV) self-sampling kits has an effect on screening participation among various socioeconomic groups and to determine if two invitation strategies for offering self-sampling influence the participation rate equally.

Methods: The study was based on registry data that were applied to data from a randomized controlled trial $(n=9,791)$ measuring how offering HPV self-sampling affected screening participation. The women received either 1) a self-sampling kit mailed directly to their homes (directly mailed group); 2) an invitation to order the kit (opt-in group); or 3) a standard second reminder to attend regular cytology screening (control group). The participation data were linked to registries containing socioeconomic information.

Results: Women in the directly mailed group participated significantly more than women in the control group, regardless of their socioeconomic status, but the largest effects were observed in Western immigrants (participation difference $[\mathrm{PD}]=18.1 \%, 95 \% \mathrm{CI}=10.2 \%-26.0 \%$ ) and social welfare recipients $(\mathrm{PD}=15.2 \%, 95 \% \mathrm{CI}=9.7 \%-20.6 \%)$. Compared with the control group, opt-in self-sampling only had an insignificant effect on participation among women who were immigrants, retired, or less educated. Western immigrants had a significantly higher increase in participation than native Danish women when kits were mailed directly compared with the opt-in strategy $(\mathrm{PD}=18.1 \%, 95 \% \mathrm{CI}=10.2 \%-26.2 \%$ and $\mathrm{PD}=5.5 \%, 95 \% \mathrm{CI}=2.9 \%-8.1 \%$, respectively, $P=0.01$ ).

Conclusion: All socioeconomic groups benefited from the directly mailed strategy in terms of higher screening participation, but Western immigrants and lower socioeconomic groups seemed to benefit the most. Immigrants and some lower socioeconomic groups only had insignificant benefits of opt-in self-sampling. The directly mailed strategy might be preferable to opt-in selfsampling because it ensures that ethnic minority groups obtain benefits of introducing HPV self-sampling in an organized cervical cancer screening program.

Trial registration: Current Controlled Trials NCT02680262. Registered February 10, 2016. Keywords: self-sampling, human papillomavirus testing, cervical cancer screening, screening participation, socioeconomic status, social class, mass screening

\section{Introduction}

Organized screening programs have reduced the incidence and mortality from cervical cancer in many Western countries. ${ }^{1-3}$ However, even in countries with free and equal access to screening for all women, social inequalities in screening participation 
exist, with non-participation being associated with foreign nationality and low socioeconomic status. ${ }^{4-6}$

As most cases of cervical cancer develop in unscreened or under-screened women, ${ }^{7-9}$ rates of cervical cancer are higher among women who are of lower socioeconomic status than among women with a higher socioeconomic status. ${ }^{10,11}$ Interventions aimed at reducing this inequality are warranted.

When testing for high-risk human papilloma virus (hrHPV) in cervical cancer screening, ${ }^{12,13}$ it is possible to increase screening participation by allowing women to use a self-sampling test kit for collection of cervicovaginal material at home before returning the sample by mail for hrHPV testing (HPV self-sampling). An overall positive effect on participation has been shown in several trials. ${ }^{14}$ Still, the effect size depends on the invitation strategy, ie, it is more effective if the kit is mailed directly to the woman's home than if it is an opt-in strategy where women must order the kit to get tested. ${ }^{14}$ This finding has recently been replicated among Danish non-participants, even if timely and convenient opt-in procedures were available for ordering the kit. ${ }^{15}$ However, it remains unclear if all socioeconomic groups may be expected to benefit from a self-sampling offer. Some studies report a positive effect of mailing self-sampling kits directly to women with a low socioeconomic status, ${ }^{16-18}$ whereas using this intervention among immigrants has yielded conflicting results. ${ }^{19-21}$ All extant studies have shortcomings, as they include only few demographic and socioeconomic factors, ${ }^{17-21}$ and rely on self-reported ${ }^{20,21}$ or area-based data, ${ }^{16-18}$ and no studies have compared the effect of mailing kits directly vs using an opt-in procedure.

Therefore, in this study, we use high-quality Danish population-based registries with individual-level data on socioeconomic factors that can be linked to data from a randomized controlled trial to measure the effect of different self-sampling invitation strategies on screening participation. The aims were to assess if HPV self-sampling has an effect on screening participation among all socioeconomic groups of non-participants, and if the two invitation strategies for offering self-sampling influence the participation rate equally.

\section{Methods}

\section{Setting}

In Denmark, cervical cancer screening is organized as a nationwide integrated program based on a call-recall invitational system, which keeps track of women in the screening population, including women entering the population, and those who are no longer subscribed to the program (eg, due to hysterectomy). ${ }^{22}$ Danish women are invited for cervical cancer screening every 3 years when aged 23-49 years and every 5 years when aged 50-64 years. ${ }^{23}$ The invitation is sent by letter advising the woman to book an appointment to have a liquid-based cervical cytology specimen collected by her general practitioner (GP). Non-participants receive up to two reminders at 3 and 6 months after the initial invitation. Women who do not participate despite reminders receive a new invitation in the next screening round if they are still in the screening age, unless they have actively opted out of the screening program. Screening, as well as follow-up and treatment, is provided free of charge for all citizens. The program follows national guidelines, but the responsibility for running the program according to these guidelines lies with the five Danish administrative regions. ${ }^{23}$ The present study was conducted in the Central Denmark Region, which covers approximately one quarter of the Danish population, with 345,000 women in the target population for cervical cancer screening. ${ }^{24,25}$ The overall participation rate, defined as having cervical cytology within 365 days after initial invitation, is currently $66 \%$, with $35 \%$ of the invited women participating within 90 days after receiving the invitation, 18\% within 90 days after the first reminder, and $8 \%$ within 90 days after the second reminder, leaving $5 \%$ to initiate their participation between 90 and 180 days after their second reminder. ${ }^{24}$ The region comprises a mix of urban and rural areas.

\section{Design}

This study was based on registry data from nationwide registries applied to data from a population-based randomized controlled effectiveness trial (Cervical HOme-based CancEr screening [CHOiCE]). In brief, the CHOiCE trial evaluated the effect on screening participation of offering self-sampling using two different invitation strategies compared with the standard second reminder for attending a regular cytology screening. ${ }^{15,26}$ The women were either 1) mailed a self-sampling kit directly to their home addresses (directly mailed group); 2) mailed an invitation to order the kit by e-mail, text message, phone, or via a website (opt-in group); or 3) mailed the standard second reminder to attend regular cytology screening (control group). The kit included a brush device ${ }^{27}$ (Evalyn ${ }^{\circledR}$ Brush, Rovers Medical Devices B.V, Oss, Netherlands) to collect a cervicovaginal sample, a leaflet, written and picture-based instructions on how to obtain and mail the sample, and a prestamped return envelope addressed to the laboratory, where the self-sample was hrHPV tested. ${ }^{26}$ All study material was written in Danish. Women in the intervention groups received identical information about HPV and cervical cancer and were also informed about the 
opportunity to attend regular cytology screening. The trial was performed within the Danish organized cervical cancer screening program between March 2016 and May 2017. Details and results of the $\mathrm{CHOiCE}$ trial, including participation stratified by age groups and screening history, compliance to follow-up testing among HPV-positive self-samplers and histological outcomes, are reported elsewhere. ${ }^{15,26}$

\section{Study population}

Included in the trial were all women aged 30-64 years who were due to receive the second reminder from the Central Denmark Region between March 7, 2016, and August 8, 2016 $(n=9,791)$. There were no exclusion criteria. ${ }^{26}$ A flowchart for the study population has been published elsewhere. ${ }^{15}$

\section{Data}

\section{Socioeconomic status}

Data on socioeconomic status were obtained from the population, education, and income registries operated by Statistics Denmark. ${ }^{28-31}$ Socioeconomic status was measured using civil status, ethnicity, occupation, highest completed education, 3-year average disposable household income, and residence area for the year the woman was included in the study, ie, 2016 , or by using the latest available data, ie, for household income, data from 2013, 2014, and 2015 were used.

Civil status was classified as married/cohabiting or living alone. Based on Statistics Denmark's classification, ethnicity was categorized either as native Danish, immigrants/ descendants from Western countries (EU, Andorra, Australia, Canada, Iceland, Lichtenstein, Monaco, New Zealand, Norway, San Marino, Switzerland, and the USA), or immigrants/ descendants from non-Western countries (others). ${ }^{32}$ Occupation was grouped as self-employed and chief executive, employed, social welfare recipient (including unemployment benefits, social security, and sick leave), retired (including disability pensioners and state pensioners), or other. According to the UNESCO Classification of Education, highest completed education was categorized into three levels: low level ( $\leq 10$ year), medium level ( $11-15$ years), and high level ( $>15$ years). ${ }^{33}$ To account for yearly variations in income, we calculated the average 3-year disposable household income using the Organization for Economic Co-operation and Development (OECD)-modified scale. ${ }^{34}$ Based on increasing tertiles and rounded to the nearest 100 Euros, the household income was categorized as: low ( $\leq 26,100$ Euros), middle ( $>26,100$ to $\leq 35,700$ Euros), and high ( $>35,700$ Euros). Residence area was measured using EUROSTAT's DEGURBA variable, transferred into a Danish context by Statistics
Denmark, using the woman's municipality code..$^{35,36}$ Thus, residence was grouped into urban area (densely populated areas: at least $50 \%$ of the population lives in urban centers), mixed rural/urban area (intermediate density areas: less than $50 \%$ of the population lives in rural grid cells and less than $50 \%$ of the population lives in urban centers), or rural area (thinly populated area: more than $50 \%$ of the population lives in rural grid cells). ${ }^{35,36}$

\section{Participation}

In the CHOiCE trial, data on participation after the second reminder were collected from the Danish Pathology Data Bank (DPDB). The DPDB is a nationwide registry, which contains records of all pathology specimens, including cervical cytology samples and self-samples; it has been highly complete since the mid-2000s. ${ }^{37,38}$ Participation in the CHOiCE trial was defined as returning a self-sample or attending regular cytology screening at the GP within 180 days after receiving the second reminder. ${ }^{15,26}$

\section{Data handling}

This study used individual-level record linkage of data, which is possible owing to the unique civil personal registration (CPR) number that is assigned to each Danish citizen upon birth and to residents upon immigration. ${ }^{39}$ The CPR number is registered at every contact with the health care system (included screening), and background data related to each CPR number are registered with Statistics Denmark and are available for research purposes. ${ }^{29}$

\section{Statistical analysis}

Descriptive statistics (numbers and proportions) were used to compare the baseline socioeconomic characteristics of the women in the intervention groups and the control group. The participation rate in each group was calculated using intention-to-treat analysis. The effect of the interventions was measured by estimating the absolute difference in participation rate (PD) and participation ratio (RR), followed by $95 \%$ confidence intervals (CIs) in the intervention groups compared with the control group. We also compared the two intervention groups to see if there was any difference in effects. Furthermore, to determine if the effect of the interventions was modified by socioeconomic status, we used generalized linear models from the binary family to test for interaction on the absolute scale and the ratio scale. $P$-values were derived from the Wald test.

All analyses were performed using STATA version 14 (StataCorp LP, College Station, TX, USA). 


\section{Approval}

The study was approved by the Danish Data Protection Agency (journal no: 1-16-02-495-15) and by the Danish Health Authorities (journal no: 3-3013-1407/1) and achieved ethical clearance at the Central Denmark Region Committees on Health Research Ethics (journal no.: 1-10-72-259-15).

\section{Results}

\section{Study population}

Our study population included 9,791 women due to receiving a second reminder in the Central Denmark Region during the study period. These women were randomized into three groups. The baseline socioeconomic characteristics were well-balanced between the three groups (Table 1), and the distribution of age has previously been reported to be similar

Table I Baseline socioeconomic characteristics of the study population

\begin{tabular}{|c|c|c|c|}
\hline & $\begin{array}{l}\text { Directly } \\
\text { mailed group } \\
(\mathrm{N}=3,265) \\
\end{array}$ & $\begin{array}{l}\text { Opt-in } \\
\text { group } \\
(\mathrm{N}=3,264)\end{array}$ & $\begin{array}{l}\text { Control } \\
\text { group } \\
(\mathrm{N}=3,262) \\
\end{array}$ \\
\hline & n (\%) & n (\%) & n (\%) \\
\hline \multicolumn{4}{|l|}{ Civil status } \\
\hline Married/cohabiting & $2,256(69.1)$ & $2,255(69.1)$ & $2,281(69.9)$ \\
\hline Living alone & $974(29.8)$ & $969(29.7)$ & $955(29.3)$ \\
\hline \multicolumn{4}{|l|}{ Ethnicity } \\
\hline Danish & $2,703(82.8)$ & $2,684(82.2)$ & $2,656(8 I .4)$ \\
\hline Western immigrants & $210(6.4)$ & $231(7.1)$ & $24 I(7.4)$ \\
\hline Non-Western immigrants & $316(9.7)$ & $308(9.4)$ & $338(10.4)$ \\
\hline \multicolumn{4}{|l|}{ Occupation } \\
\hline \multicolumn{4}{|l|}{ executive } \\
\hline Employed & $2,100(64.3)$ & $2,088(63.9)$ & $2,07 \mid(63.5)$ \\
\hline Social welfare recipient ${ }^{\mathrm{a}}$ & $452(13.8)$ & $429(13.1)$ & $491(15.1)$ \\
\hline Retired $^{\mathrm{b}}$ & $302(9.3)$ & $317(9.7)$ & $292(8.9)$ \\
\hline Other & $232(7.1)$ & $242(7.4)$ & $232(7.1)$ \\
\hline \multicolumn{4}{|l|}{ Education (years) ${ }^{c}$} \\
\hline$\leq 10$ & $56 \mid(17.2)$ & $577(17.7)$ & $588(18.0)$ \\
\hline $11-15$ & $2,105(64.5)$ & $2,058(63.1)$ & $2,055(63.0)$ \\
\hline$>15$ & $301(9.2)$ & $307(9.4)$ & $295(9.0)$ \\
\hline \multicolumn{4}{|l|}{ Income $e^{d}$} \\
\hline Low & $\mathrm{I}, 033(3 \mathrm{I} .6)$ & $\mathrm{I}, 005(30.8)$ & I,023 (3I.4) \\
\hline Middle & $1,024(31.4)$ & $1,002(30.7)$ & 1,040 \\
\hline High & $\mathrm{I}, 012(31.0)$ & $I, 04 \mid(3 I .9)$ & $996(30.5)$ \\
\hline \multicolumn{4}{|l|}{ Residence area } \\
\hline Urban & $787(24.1)$ & $845(25.9)$ & $840(25.8)$ \\
\hline Mixed rural/urban & $1,059(32.4)$ & $\mathrm{I}, 036(3 \mathrm{I} .7)$ & $\mathrm{I}, 023(3 \mathrm{I} .4)$ \\
\hline Rural & $\mathrm{I}, 384(42.4)$ & $\mathrm{I}, 343(4 \mathrm{I} .2)$ & $1,373(42.1)$ \\
\hline \multicolumn{4}{|c|}{$\begin{array}{l}\text { Notes: Number and proportion vary because of missing data. No statistically } \\
\text { significant differences in the distribution of the socioeconomic characteristics } \\
\text { were found between the groups (chi-square test }>0.05 \text { ). Including social security, } \\
\text { unemployment benefit, and sick leave. IIncluding disability pension and state pension. } \\
\text { cHighest obtained educational level. }{ }^{\circ} O E C D \text {-adjusted disposable household income: } \\
\text { see Methods section. }\end{array}$} \\
\hline
\end{tabular}

across the groups. ${ }^{15}$ The majority of women were characterized by being married/cohabiting, native Danish, employed, having a middle level of education, and residing in rural areas (Table 1). The three major Western immigrant populations originated from Poland (18.3\%), Romania (14.8\%), and Lithuania (8.2\%), while the three major non-Western immigrant populations originated from Syria (12.6\%), Turkey (10.5\%), and Lebanon (7.9\%).

\section{Participation in relation to socioeconomic status}

Overall, women assigned to the directly mailed group more often participated than those assigned to the control group, regardless of their civil status, ethnicity, occupation, education, income, and residence (differences ranging from $8.0 \%$ to $18.1 \%$ ) (Table 2). Only women being self-employed and chief executive did not reach statistical significance $(\mathrm{PD}=10.1 \%$, $95 \% \mathrm{CI}=-0.3 \%-20.5 \%)$. Compared with the control group, the greatest differences in participation by mailing the kit directly were found for Western immigrants and social welfare recipients $(\mathrm{PD}=18.1 \%, 95 \% \mathrm{CI}=10.2 \%-26.0 \%$ and $\mathrm{PD}=15.2 \%, 95 \% \mathrm{CI}=9.7 \%-20.6 \%$, respectively). Regarding ethnicity, a stronger effect of the directly mailed intervention was observed among Western and non-Western immigrants than among native Danish women. However, these differences were not statistically significant ( $P$-values for interaction: absolute scale $=0.36$ and relative scale $=0.08)$ (Table 2 ).

Women assigned to opt-in self-sampling also had a higher participation rate than women assigned to the control group. This difference was independent of socioeconomic status, except among women who were Western immigrants (Table 2). However, no statistically significant effect on participation was seen between the opt-in and the control group among women who were immigrants, self-employed and chief executive, retired, or who had a low or high level of education. For the opt-in group, the largest effects were found for social welfare recipients and women with a middle level of education $(\mathrm{PD}=7.8 \%, 95 \% \mathrm{CI}=2.6 \%-13.1 \%$ and $\mathrm{PD}=7.3 \%, 95 \% \mathrm{CI}=4.5 \%-10.1 \%$, respectively).

For all socioeconomic factors, mailing the kit directly to women produced a higher participation than opt-in self-sampling, with differences ranging from $4.2 \%-18.1 \%$ (Table 2). Still, we observed no statistically significant differences between the directly mailed and the opt-in group in participation among women who were self-employed and chief executive, retired, or who had a low or high level of education. Compared with the opt-in self-sampling, mailing the kit directly to Western immigrants produced a two- 


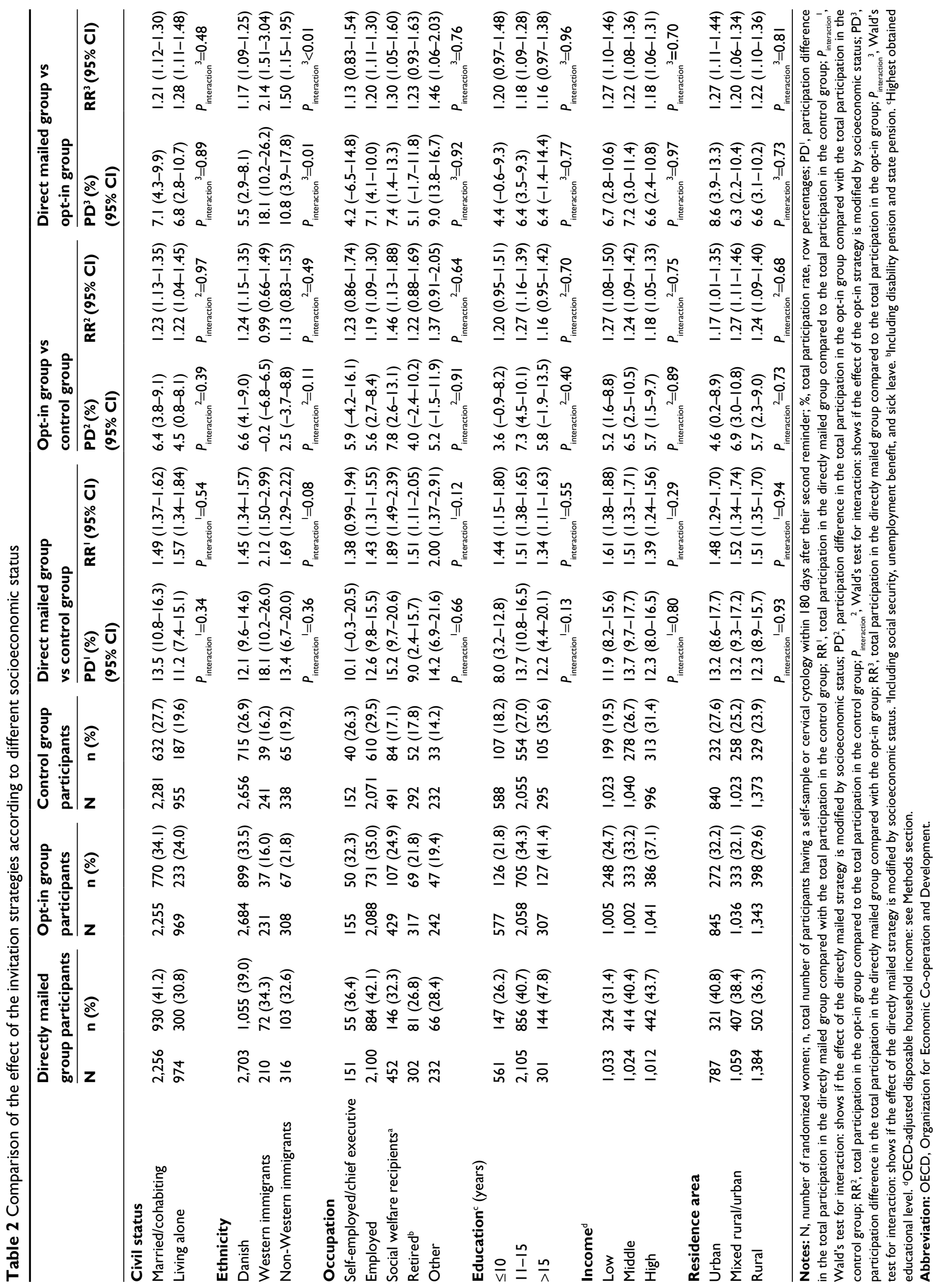


times higher participation rate $(16.0 \%$ vs $34.3 \%, \mathrm{RR}=2.14$, 95\% CI=1.51-3.04). A similar, though less pronounced, effect was seen among non-Western immigrants $(21.8 \%$ vs $32.6 \%, \mathrm{RR}=1.50,95 \% \mathrm{CI}=1.15-1.95)$. The participation rate increased statistically significantly more among Western immigrants than among native Danish women when kits were mailed directly compared with the opt-in self-sampling modality $(P$-values for interaction: absolute scale $=0.01$ and relative scale $<0.01$ ) (Table 2 ).

\section{Participation by cytology screening or self-sampling according to socioeconomic status}

Figure 1 shows the percentage of women in each group who participated by regular cytology screening or by selfsampling according to socioeconomic status. In the directly mailed group, self-sampling increased the participation rate, but it also resulted in fewer women attending regular cytology screening. This was least pronounced for immigrants and social welfare recipients, where the participation rate in regular cytology screening was almost unaffected. In the opt-in group, the same trends were observed. The participation was least affected among non-Western immigrants and women with a middle level of education and a low income. For social welfare recipients, a shift toward higher regular cytology participation was observed. When Western immigrants had the choice between self-sampling and regular cytology screening, the majority chose self-sampling over the regular cytology screening $(20.0 \%$ vs $14.3 \%)$. The opposite trend was observed for non-Western immigrants, who chose the regular cytology screening over self-sampling (17.7\% vs $14.9 \%$ ). In the opt-in group, all socioeconomic groups chose the regular cytology screening over self-sampling.

\section{Discussion}

\section{Main findings}

This registry-based study revealed that, across all socioeconomic groups, mailing the self-sampling kit directly to women yielded a higher screening participation than a standard second reminder to attend regular cytology screening by the GP: the largest increase in participation was observed among Western immigrants and social welfare recipients. Inviting women to opt-in self-sampling also yielded a higher participation rate than the second reminder across almost all socioeconomic groups, but the effect was smaller than seen for the directly mailed group. Western immigrants had a significantly higher increase in participation than native Danish women when kits were mailed directly compared with the opt-in strategy.

\section{Strengths and limitations}

This study included socioeconomic register-based variables of a high quality and validity, enabling us to give a precise description of the women participating in screening when

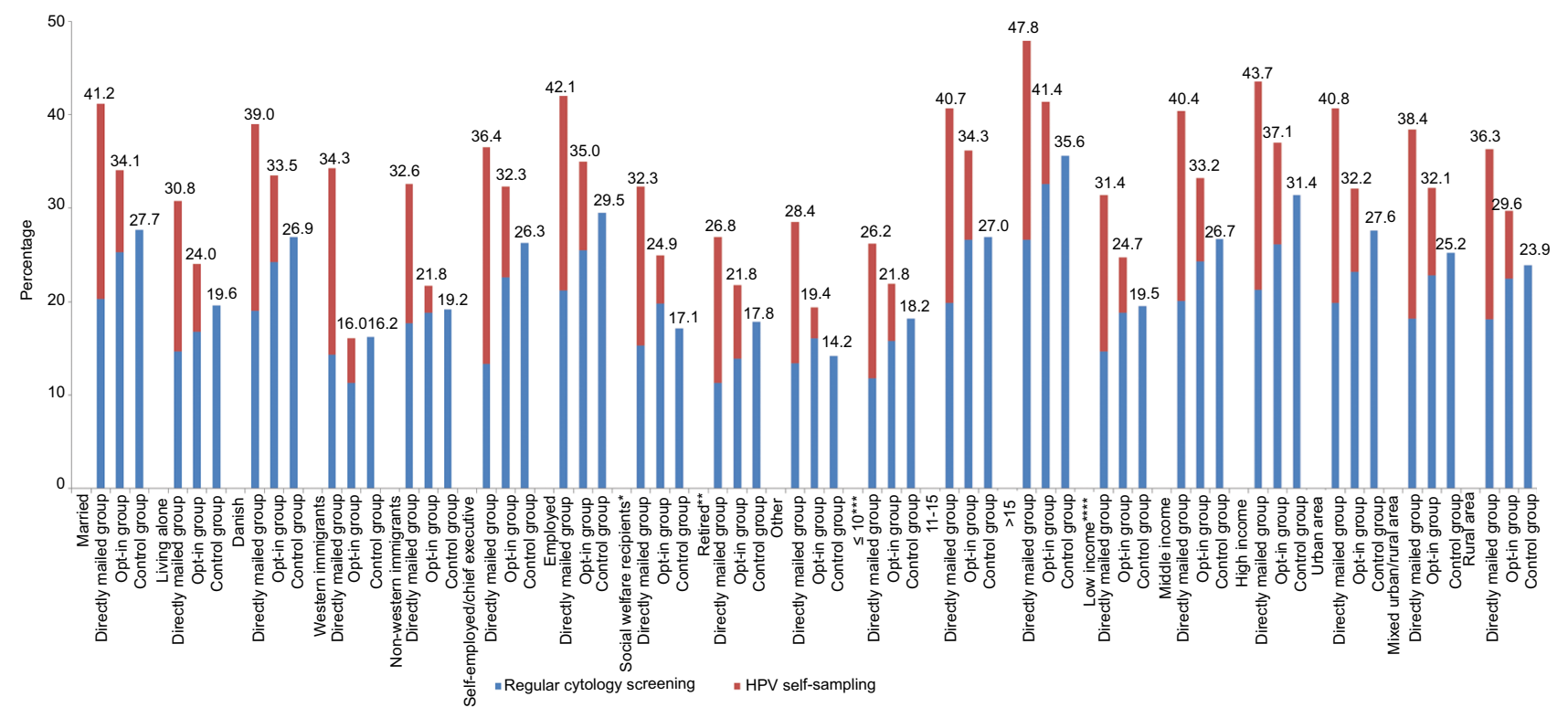

Figure I Participation rate by regular cytology screening or HPV self-sampling stratified by socioeconomic status.

Notes: *Including social security, unemployment benefit, and sick leave. **Including disability pension and state pension. ***Highest obtained educational level. ****OECDadjusted disposable household income: see Methods section.

Abbreviations: HPV, human papilloma virus; OECD, Organization for Economic Co-operation and Development. 
they were given the choice between one of the two selfsampling strategies and regular cytology screening. The use of data on participation from the DPDB that has highly valid records on all pathology specimens minimized any risk of information bias. ${ }^{37,38}$ The randomized controlled design secured an equal distribution of known and unknown confounders; thus, the results were unlikely to be explained by confounding. Furthermore, the study was embedded into a routine screening setting, which enhanced its validity and generalizability.

Nevertheless, this study has potential limitations. Missing data are a potential selection problem. The proportion of missing data ranged from $0.7 \%$ for the variable occupation to $9.0 \%$ for data on education. This latter figure was primarily due to missing data for immigrant women. ${ }^{30}$ However, the distribution of missing data on education was similar for both participants and non-participants in the three groups, indicating that the estimates should be unbiased. Some of the stratified analyses contained a small number of women and have relatively wide CIs, so these results should be interpreted with caution. Women's compliance with follow-up on HPV positive self-sample results is essential for the self-sampling offer to be efficient. Thus, it would have been interesting to stratify this outcome by the socioeconomic markers. We previously reported the compliance to be high for the total study population $(90.7 \%) .{ }^{15}$ However, stratification was not possible due to limited data.

\section{Interpretation and comparison with previous studies}

As in other countries, ${ }^{4,5}$ low participation in the Danish screening program is associated with having a foreign nationality and a low socioeconomic status. ${ }^{6}$ Still, our results showed that all groups of women benefited from the directly mailed intervention, making this invitation strategy successful, independently of socioeconomic status. The greatest effects were seen among some hard-to-reach groups, ie, immigrants and social welfare recipients. This finding is in line with prior randomized controlled trials. ${ }^{16-18}$ However, the directly mailed intervention did not manage to level out the lower participation rates among immigrants and lower socioeconomic groups, as participation was lowest in these groups, even after the intervention.

Compared with the control group, direct mailing of the kits produced a slightly greater increase in participation for Western immigrants (18\%) than for non-Western immigrants (13\%). Although consistent with one Dutch trial, ${ }^{19}$ this finding is in contrast to two Finnish trials that found no significant effect of mailing the kit directly to immigrants (Western or non-Western) compared with the first reminder for regular cytology screening. ${ }^{20,21}$ These conflicting results could be related to differences in the ethnic profiles of nonparticipants between countries. It may be speculated if the lower effect among non-Western immigrants in our study might be explained by limited knowledge about screening in general, ${ }^{40}$ or if it is rooted in cultural and language barriers $^{41,42}$ or mistrust in one's own ability to obtain the selfsample correctly. ${ }^{41-44}$ However, our study was not designed to investigate this.

Surprisingly, we found that most non-Western immigrants chose to attend regular cytology screening rather than taking the self-sample, even when the kits were mailed directly to their home. An explanation for this may be similar to the one reported from English focus group studies showing that Muslim and Hindu women preferred attending cytology screening performed by a female professional rather than to collect a self-sample. ${ }^{41,42}$ The studies revealed that, while these women believed that self-sampling would remove some of the barriers to screening, they did not have trust in their own ability to take the self-sample correctly and worried that a HPV-positive test result could cause relationship problems. ${ }^{41,42,45}$ We have no way of knowing if this is also the case in our population of non-Western immigrants. The picture-based instructions showing how to collect self-samples should be self-explaining, but all written information in our study was in Danish, and language barriers may, therefore, be another explanation. Nevertheless, our data showed a good effect from offering non-Western immigrants the possibility of self-sampling, but self-sampling may not be the only answer to meet their needs.

Compared with the control group, opt-in self-sampling improved participation across almost all groups of women. Still, it proved overall to be less effective than direct mailing of kits. Opt-in self-sampling had no or only an insignificant effect on participation in some hard-to-reach groups, ie, immigrants, retired, and less educated women.

Especially, we found that mailing the kit directly doubled the participation rate among Western immigrants compared with the opt-in strategy, and a similar trend was observed among non-Western immigrants. Western immigrants had an even higher increase in participation than native Danish women when the kits were mailed directly compared with the opt-in strategy. Hence, mailing the kits directly might reduce the socioeconomic status gradient in screening participation. Even though the opt-in strategy may reduce costs and waste 
of unused self-sampling kits, the directly mailed strategy might be preferable.

A Danish study demonstrated no increased risk of cervical cancer in immigrants compared with the native population, possibly due to small numbers. ${ }^{11}$ However, Swedish and Dutch studies reported an increased risk among immigrants; ${ }^{46-48}$ especially among those from Poland, ${ }^{47}$ Central Africa, and Central America. ${ }^{46,48}$ These subpopulations may have a higher background risk of cervical cancer due to a high prevalence of $\mathrm{HPV}^{49}$ and poor access to cervical cancer screening ${ }^{50}$ in their home countries, while low compliance to screening in the new country may be a supplemental explanation. This argument supports that engaging immigrants in screening by offering them the possibility of self-sampling as an alternative to regular cytology screening might potentially reduce the overall burden of the disease.

\section{Conclusion}

All socioeconomic groups benefited from the directly mailed strategy in terms of higher screening participation, but Western immigrants and lower socioeconomic groups appeared to benefit the most. Immigrants and some lower socioeconomic groups had only insignificant benefits of opt-in self-sampling. The directly mailed strategy might be preferable over opt-in self-sampling, because it ensures that ethnic minority groups obtain the same or even better benefits from introducing selfsampling in the Danish organized cervical cancer screening program than the rest of the population.

\section{Availability of data and materials}

Data are available from the Department of Public Health Programmes, Randers Regional Hospital, for researchers who meet the criteria for access to patients' confidential data.

\section{Acknowledgment}

This study was funded by the Health Research Fund of the Central Denmark Region, the Health Foundation, the LSB Foundation, the Family Hede Nielsen's Foundation, the Krista and Viggo Petersen's Foundation, and the Aragon Foundation.

\section{Author contributions}

All authors made substantial contributions to conception and design, acquisition of data, or analysis and interpretation of data; took part in drafting the article or revising it critically for important intellectual content; gave final approval of the version to be published; and agree to be accountable for all aspects of the work.

\section{Disclosure}

Axlab, the Danish manufacturer of the Evalyn ${ }^{\circledR}$ Brush, and Roche, the manufacturer of the $\operatorname{Cobas}^{\circledR} 4800$ HPV DNA assay, provided self-sampling devices and test kits for the CHOiCE trial. According to the contract between the manufacturers and the Department of Public Health Programmes, Randers Regional Hospital, Denmark, Axlab and Roche had no influence on the scientific process and no editorial rights pertaining to this manuscript. The authors retained the right to submit the manuscript. None of the authors were compensated for their work on this study, have any shares in the manufacturers' companies, or received bonuses from any of the manufacturers. The authors report no other conflicts of interest in this work.

\section{References}

1. Arbyn M, Raifu AO, Weiderpass E, Bray F, Anttila A. Trends of cervical cancer mortality in the member states of the European Union. Eur $J$ Cancer. 2009;45(15):2640-2648.

2. Andrae B, Andersson TM, Lambert PC, et al. Screening and cervical cancer cure: population based cohort study. BMJ. 2012;344:e900.

3. Vaccarella S, Franceschi S, Engholm G, Lönnberg S, Khan S, Bray F. 50 years of screening in the Nordic countries: quantifying the effects on cervical cancer incidence. Br J Cancer. 2014;111(5):965-969.

4. Webb R, Richardson J, Esmail A, Pickles A. Uptake for cervical screening by ethnicity and place-of-birth: a population-based cross-sectional study. J Public Health. 2004;26(3):293-296.

5. van Leeuwen AW, de Nooijer P, Hop W. Screening for cervical carcinoma: participation and results for ethnic groups and socioeconomic status. Cancer. 2005;105(5):270-276.

6. Kristensson JH, Sander BB, von Euler-Chelpin M, Lynge E. Predictors of non-participation in cervical screening in Denmark. Cancer Epidemiol. 2014;38(2):174-180.

7. Andrae B, Kemetli L, Sparén P, et al. Screening-preventable cervical cancer risks: evidence from a nationwide audit in Sweden. J Natl Cancer Inst. 2008;100(9):622-629.

8. Ingemann-Hansen O, Lidang M, Niemann I, et al. Screening history of women with cervical cancer: a 6-year study in Aarhus, Denmark. Br J Cancer. 2008;98(7):1292-1294.

9. Spence AR, Goggin P, Franco EL. Process of care failures in invasive cervical cancer: systematic review and meta-analysis. Prev Med. 2007;45(2-3):93-106.

10. Parikh S, Brennan P, Boffetta P. Meta-analysis of social inequality and the risk of cervical cancer. Int J Cancer. 2003;105(5):687-691.

11. Jensen KE, Hannibal CG, Nielsen A, et al. Social inequality and incidence of and survival from cancer of the female genital organs in a population-based study in Denmark, 1994-2003. Eur J Cancer. 2008;44(14):2003-2017.

12. Cuzick J, Clavel C, Petry KU, et al. Overview of the European and North American studies on HPV testing in primary cervical cancer screening. Int $J$ Cancer. 2006;119(5):1095-1101.

13. Ronco G, Dillner J, Elfström KM, et al. Efficacy of HPV-based screening for prevention of invasive cervical cancer: follow-up of four European randomised controlled trials. Lancet. 2014;383(9916):524-532.

14. Verdoodt F, Jentschke M, Hillemanns P, Racey CS, Snijders PJ, Arbyn M. Reaching women who do not participate in the regular cervical cancer screening programme by offering self-sampling kits: a systematic review and meta-analysis of randomised trials. Eur J Cancer. 2015;51(16): $2375-2385$. 
15. Tranberg M, Bech BH, Blaakær J, Jensen JS, Svanholm H, Andersen B. Preventing cervical cancer using HPV self-sampling: direct mailing of test-kits increases screening participation more than timely opt-in procedures - a randomized controlled trial. BMC Cancer. 2018;18(1):273.

16. Sancho-Garnier H, Tamalet C, Halfon P, et al. HPV self-sampling or the Pap-smear: a randomized study among cervical screening nonattenders from lower socioeconomic groups in France. Int $J$ Cancer. 2013;133(11):2681-2687.

17. Sultana F, English DR, Simpson JA, et al. Home-based HPV selfsampling improves participation by never-screened and under-screened women: results from a large randomized trial (iPap) in Australia. Int $J$ Cancer. 2016;139(2):281-290.

18. Cadman L, Wilkes S, Mansour D, et al. A randomized controlled trial in non-responders from Newcastle upon Tyne invited to return a selfsample for Human Papillomavirus testing versus repeat invitation for cervical screening. J Med Screen. 2015;22(1):28-37.

19. Gök M, Heideman DA, van Kemenade FJ, et al. Offering self-sampling for human papillomavirus testing to non-attendees of the cervical screening programme: characteristics of the responders. Eur J Cancer. 2012;48(12):1799-1808.

20. Virtanen A, Nieminen P, Luostarinen T, Anttila A. Self-sample HPV tests as an intervention for nonattendees of cervical cancer screening in Finland: a randomized trial. Cancer Epidemiol Biomarkers Prev. 2011;20(9):1960-1969.

21. Virtanen A, Anttila A, Luostarinen T, Nieminen P. Self-sampling versus reminder letter: effects on cervical cancer screening attendance and coverage in Finland. Int J Cancer. 2011;128(11):2681-2687.

22. Lynge E, Andersen B, Christensen J, et al. Cervical screening in Denmark - a success followed by stagnation. Acta Oncol. 2018;57(3):354-361.

23. The Danish Health and Medicines Authority. Screening for livmoderhalskræft-anbefalinger 2012. [Cervical cancer screening-recommendations]. Copenhagen: DHMA; 2012 [in Danish with English summary].

24. Danish Quality Database for Cervical Cancer Screening (DKLS). Danish Quality Database for Cervical Cancer Screening, Annual Report 2016. Aarhus: DKLS; 2016. Available from: https://www.sundhed.dk/ content/cms/82/4682_dkls_\%C3\%A5rsrapport2016_offentligversion. pdf. Accessed December 2017.

25. Statistics Denmark [homepage on the Internet]. Available from: www. statistikbanken.dk. Accessed September 9, 2017. Danish.

26. Tranberg M, Bech BH, Blaakær J, Jensen JS, Svanholm H, Andersen B. Study protocol of the CHOiCE trial: a three-armed, randomized, controlled trial of home-based HPV self-sampling for non-participants in an organized cervical cancer screening program. BMC Cancer. 2016;16(1):835.

27. van Baars R, Bosgraaf RP, Ter Harmsel BW, Melchers WJ, Quint WG, Bekkers RL. Dry storage and transport of a cervicovaginal self-sample by use of the Evalyn Brush, providing reliable human papillomavirus detection combined with comfort for women. J Clin Microbiol. 2012;50(12): 3937-3943.

28. Baadsgaard M, Quitzau J. Danish registers on personal income and transfer payments. Scand J Public Health. 2011;39(7 Suppl): 103-105.

29. Thygesen LC, Daasnes C, Thaulow I, Brønnum-Hansen H. Introduction to Danish (nationwide) registers on health and social issues: structure, access, legislation, and archiving. Scand J Public Health. 2011;39(7 Suppl):12-16.

30. Jensen VM, Rasmussen AW. Danish education registers. Scand J Public Health. 2011;39(7 Suppl):91-94.

31. Norredam M, Kastrup M, Helweg-Larsen K. Register-based studies on migration, ethnicity, and health. Scand J Public Health. 2011;39(7 Suppl):201-205.

32. Statistics Denmark [webpage on the Internet]. Definition of immigrants and descendants. Available from: http://www.dst.dk/da/TilSalg/ Forskningsservice/Dokumentation/hoejkvalitetsvariable/udlaendinge/ ie-type. Accessed September 9, 2017. Danish.
33. UNESCO Institute for Statistics. International Standard Classification of Education ISCED 2011. Montreal, QC: UNESCO Institute for Statistics; 2012. Available from: http://uis.unesco.org/sites/default/files/ documents/international-standard-classification-of-education-isced2011-en.pdf. Accessed September 9, 2017.

34. Organisation for Economic Co-operation and Development. What are equivalence scales? Paris: OECD. Available from: http://www.oecd. org/els/soc/OECD-Note-EquivalenceScales.pdf. Accessed September 9, 2017.

35. Eurostat (European Statistics). Definition of EUROSTAT's DEGURBA variable. Available from: http://ec.europa.eu/eurostat/documents/4337659/4337763/RYB2016-C00M1.pdf. Accessed September 9, 2017.

36. Degurba variable. Statistics Denmark. Available from: https://www. dst.dk/da/Statistik/dokumentation/nomenklaturer/degurba---danmarksstatistik. Accessed September 9, 2017.

37. Dugué PA, Lynge E, Bjerregaard B, Rebolj M. Non-participation in screening: the case of cervical cancer in Denmark. Prev Med. 2012;54(3-4):266-269.

38. Erichsen R, Lash TL, Hamilton-Dutoit SJ, Bjerregaard B, Vyberg M, Pedersen L. Existing data sources for clinical epidemiology: the Danish National Pathology Registry and Data Bank. Clin Epidemiol. 2010;2:51-56.

39. Schmidt M, Pedersen L, Sørensen HT. The Danish Civil Registration System as a tool in epidemiology. Eur J Epidemiol. 2014;29(8): 541-549.

40. Marlow LA, Waller J, Wardle J. Barriers to cervical cancer screening among ethnic minority women: a qualitative study. J Fam Plann Reprod Health Care. 2015;41(4):248-254.

41. Szarewski A, Cadman L, Ashdown-Barr L, Waller J. Exploring the acceptability of two self-sampling devices for human papillomavirus testing in the cervical screening context: a qualitative study of Muslim women in London. J Med Screen. 2009;16(4):193-198.

42. Cadman L, Ashdown-Barr L, Waller J, Szarewski A. Attitudes towards cytology and human papillomavirus self-sample collection for cervical screening among Hindu women in London, UK: a mixed methods study. J Fam Plann Reprod Health Care. 2015;41(1):38-47.

43. Waller J, McCaffery K, Forrest S, et al. Acceptability of unsupervised HPV self-sampling using written instructions. J Med Screen. 2006;13(4):208-213.

44. Forrest S, McCaffery K, Waller J, et al. Attitudes to self-sampling for HPV among Indian, Pakistani, African-Caribbean and white British women in Manchester, UK. J Med Screen. 2004;11(2):85-88.

45. Madzima TR, Vahabi M, Lofters A. Emerging role of HPV self-sampling in cervical cancer screening for hard-to-reach women: focused literature review. Can Fam Physician. 2017;63(8):597-601.

46. Azerkan F, Zendehdel K, Tillgren P, Faxelid E, Sparén P. Risk of cervical cancer among immigrants by age at immigration and followup time in Sweden, from 1968 to 2004. Int J Cancer. 2008;123(11): 2664-2670.

47. Beiki O, Allebeck P, Nordqvist T, Moradi T. Cervical, endometrial and ovarian cancers among immigrants in Sweden: importance of age at migration and duration of residence. Eur J Cancer. 2009;45(1): $107-118$.

48. Arnold M, Aarts MJ, van der Aa M, Visser O, Coebergh JW. Investigating cervical, oesophageal and colon cancer risk and survival among migrants in The Netherlands. Eur J Public Health. 2013;23(5): 867-873.

49. Bruni L, Diaz M, Castellsagué X, Ferrer E, Bosch FX, de Sanjosé S. Cervical human papillomavirus prevalence in 5 continents: metaanalysis of 1 million women with normal cytological findings. $J$ Infect Dis. 2010;202(12):1789-1799.

50. Arbyn M, Castellsagué X, de Sanjosé S, et al. Worldwide burden of cervical cancer in 2008. Ann Oncol. 2011;22(12):2675-2686. 


\section{Publish your work in this journal}

Clinical Epidemiology is an international, peer-reviewed, open access, online journal focusing on disease and drug epidemiology, identification of risk factors and screening procedures to develop optimal preventative initiatives and programs. Specific topics include: diagnosis, prognosis, treatment, screening, prevention, risk factor modification,

Submit your manuscript here: https://www.dovepress.com/clinical-epidemiology-journa systematic reviews, risk and safety of medical interventions, epidemiology and biostatistical methods, and evaluation of guidelines, translational medicine, health policies and economic evaluations. The manuscript management system is completely online and includes a very quick and fair peer-review system, which is all easy to use. 